\title{
The association of diabetes with all-cause mortality in patients with end-stage renal disease compared to the general population in Poland - a comparative analysis
}

Waldemar Wierzba ${ }^{1}$, Andrzej Śliwczyński ${ }^{1}$, Waldemar Karnafel ${ }^{1}$, Mariusz Gujski ${ }^{2}$, Maciej Słodki ${ }^{3}$, Aleksandra Lusawa', Jarosław Pinkas ${ }^{4}$

${ }^{1}$ University of Humanities and Economics, Lodz, Poland

${ }^{2}$ Medical University of Warsaw, Warsaw, Poland

${ }^{3}$ Department of Prenatal Cardiology in Polish Mother's Memorial Hospital Research Institute, Lodz, Poland

${ }^{4}$ Centre of Postgraduate Medical Education, Warsaw, Poland

Submitted: 6 January 2019; Accepted: 5 April 2019

Online publication: 4 May 2020

Arch Med Sci 2022; 18 (2): 314-319

DOI: https://doi.org/10.5114/aoms.2020.94955

Copyright (c) 2020 Termedia \& Banach

\section{Abstract}

Introduction: End-stage renal disease (ESRD) is an important complication of diabetes, which is the leading cause of ESRD worldwide. The aim of the study was a comparative analysis of all-cause mortality in patients with ESRD with diagnosed diabetes mellitus (DM) and no diagnosed DM.

Material and methods: Data for the analysis were obtained from the resources of the Polish National Health Fund, and they concerned patients with endstage renal disease from the entire population of Polish patients in the period from 1.01.2011 to 31.12.2013. In addition, the period from 1.01.2012 to 31.12.2012 was analysed for two subpopulations: diabetic and non-diabetic patients.

Results: The all-cause mortality in patients with end-stage renal disease in Poland per 100,000 representatives of the general population was 17.7, 15.9 , and 12.50 persons in 2011,2012, and 2013, respectively. The all-cause mortality rates for patients with ESRD and diabetes in Poland in 2012 were more than 15 times higher, for both men and women, than the all-cause mortality rates for non-diabetic patients with ESRD. Mortality in the study group of diabetic men with ESRD amounted to $147.59 \pm 29.07 / 100,000$ men, whereas in the study group of diabetic women with ESRD it was 105.13 $\pm 26.77 / 100,000$ women. Regarding non-diabetic men with ESRD and non-diabetic women with ESRD, mortality amounted to $9.58 \pm 6.29 / 100,000$ and $6.87 \pm 2.27 / 100,000$ men and women, respectively.

Conclusions: The occurrence of diabetes in patients with ESRD significantly increases the risk of death compared to patients with ESRD without diabetes.

Key words: diabetes mellitus, end-stage renal disease, all-cause mortality.

\section{Introduction}

End-stage renal disease (ESRD) is an important complication of diabetes, which is the leading cause of ESRD worldwide [1-6]. Diabetes is the most common endocrine disease in the world, and hyperglycaemia is the leading cause of hospitalisation of patients with diabetes [7]. Diabe-

\section{Corresponding author:}

Waldemar Wierzba MD, PhD

University of Humanities

and Economics

26 Sterlinga St

90-212 Lodz, Poland

E-mail: wwierzba@post.pl 
tes has many complications that lower the quality of life, like ESRD [8-10]. It has been indicated by many researchers that chronic kidney disease can increase the risk of cardiovascular death [1, 2]. In a meta-analysis of 39 studies and 1,371,990 patients, Tonelli et al. showed that chronic kidney disease causes a higher risk of death, depending on the stage of renal failure [4]. Among patients treated with renal replacement by haemodialysis, deaths are 13-15 times more frequent compared to deaths in non-dialysed patients in the control group [11]. Mortality in patients with ESRD is higher in men than in women, and it prevails in the African-American group of patients [12]. The occurrence of diabetes and obesity in patients with chronic renal failure also increases the risk of death in this group of patients [13, 14].

In the available scientific literature, there are no publications that compare the all-cause mortality in patients with ESRD in the two subgroups of diabetic and non-diabetic patients. Our study involved an analysis of the all-cause mortality in patients with ESRD with diabetes and without diabetes in 2012 compared to general mortality in patients with ESRD in Poland in 2011-2013.

\section{Material and methods}

The authors of this article performed a retrospective, population-based study using database records of the Polish National Health Fund. Subject to analysis were data on patients with diabetes or ESRD in 2011, 2012, and 2013, which were compared to the general population in Poland, and additionally data on two subpopulations of patients: patients with diabetes and patients without diabetes, in 2012. Incidence rates were calculated on the basis of the number of patients with diabetes or ESRD and relevant census data. Besides the data from the National Health Fund (NHF), demographic data for the general population of Poland were obtained from the Central Statistical Office in Poland (Central Statistical Office, 2016). End-stage renal disease often requires hospitalisation or various forms of dialysis; therefore, an analysis of hospitalisation cases can provide a good estimate of the incidence of ESRD.

Healthcare services in Poland are financed by the NHF pursuant to the binding act [15] and the regulations of the Minister of Health arising from the act $[16,17]$. Healthcare services are provided within the framework of outpatient treatment and inpatient treatment, i.e. hospital care. Provision of healthcare services is described in detail in the regulations of the President of the NHF [18, 19]. In order to conduct an epidemiological analysis for this paper, patient information from the NHF database was used. The Polish National Health Fund settles and pays for health services provided to the patient by healthcare providers. In the database covering the period from 1.01.2011 to 31.12.2013, reports on ESRD according to the International Classification of Diseases (ICD-10): N18.0 - end-stage renal disease (ESRD) were found for the year 2011, 2012, and 2013. The Polish NHF database precludes the distinction of dialysis and non-dialysis patients with ESRD. Furthermore, reports on diabetes-related healthcare services were found in the resources of the fund for the period from 1.01.2012 to 31.12.2012. The main diagnosis in these reports was "diabetes" with the following extensions: E10.X - insulin-dependent diabetes, E11.X-non-insulin dependent diabetes, E12.X-diabetes associated with malnutrition, E13.X - other unspecified forms of diabetes, and E14.X - unspecified diabetes, or at the same time a patient bought medicine from any of these groups: A10A.X (insulin), A10B.X (oral antidiabetic drugs), specialised diagnostic tests. The dates of patient deaths were obtained from the Central List of the Insured.

\section{Statistical analysis}

The data were analysed using PQStat 1.6 statistical software of the Polish company PQStat Software. Additionally, Student's t-test was applied for independent groups. Odds ratio (OR), confidence interval, and statistical significance were also calculated. The differences were considered significant at the $95 \%$ confidence level $(p<0.05)$.

\section{Results}

According to the data obtained from the Central Statistical Office, there were 38,501,000 people living in Poland in 2011, including 18,432,000 men and 20,069,000 women. In 2012 the number of inhabitants amounted to $38,533,789$ people, including 18,651,441 men and 19,882,348 women. In 2013 there were $38,793,441$ people living in Poland, including 18,629,535 men and 20,163,906 women[20]. The number of patients with diabetes in Poland in 2012 amounted to $2,227,453$, including 975,364 men and 1,252,089 women. 36,306,336 people in Poland did not suffer from diabetes in 2012, including $17,676,077$ men and 18,630,259 women [21]. The total male mortality rate per 100,000 representatives and total male number of deaths were higher in all years than the female mortality rate (Table I) in patients diagnosed with ESRD by gender in 2011, 2012, and 2013. A comparison between the all-cause mortality in diabetic patients with ESRD (ICD-10: N18.0 and E10-E14.X) and the non-diabetic population in Poland in 2012 showed significant differences between populations of diabetic and non-diabetic patients. No diabetes was found in $53.24 \%$ of male and female patients who died of ESRD. $51.94 \%$ of those who were diabetic and died of ESRD were 
Table I. All-cause mortality rates per 100,000 representatives and number of deaths in patients with end-stage renal disease in Poland in 2011-2013, based on the database of the National Health Fund and the Central List of the Insured by gender and the general population

\begin{tabular}{|ccccccccc|}
\hline Year & $\begin{array}{c}\text { Total both } \\
\text { genders } \\
\text { mortality } \\
\text { per 100,000 }\end{array}$ & $\begin{array}{c}\text { Total male } \\
\text { mortality } \\
\text { per 100,000 }\end{array}$ & $\begin{array}{c}\text { Total } \\
\text { female } \\
\text { mortality } \\
\text { per 100,000 }\end{array}$ & $\begin{array}{c}\text { Total } \\
\text { number } \\
\text { of deaths }\end{array}$ & $\begin{array}{c}\text { Total } \\
\text { number } \\
\text { of deaths } \\
\text { - male }\end{array}$ & $\begin{array}{c}\text { Total } \\
\text { number } \\
\text { of deaths } \\
\text { - female }\end{array}$ & $\begin{array}{c}\text { Percentage } \\
\text { male }\end{array}$ & $\begin{array}{c}\text { Percentage } \\
\text { female }\end{array}$ \\
\hline 2011 & 24.81 & 28.67 & 21.19 & 9563 & 5349 & 4214 & 55.9 & 44.1 \\
\hline 2012 & 23.34 & 26.35 & 20.52 & 8994 & 4914 & 4080 & 54.6 & 45.4 \\
\hline 2013 & 20.58 & 23.52 & 17.82 & 7922 & 4381 & 3541 & 55.3 & 44.7 \\
\hline
\end{tabular}

Table II. The number of deaths in diabetic and non-diabetic patients with end-stage renal disease (ESRD) in Poland in 2012 by gender, based on the National Health Fund and the Central List of the Insured

\begin{tabular}{|lcccc|}
\hline \multirow{2}{*}{ Parameter } & \multicolumn{2}{c}{ Patients with ESRD with diabetes } & \multicolumn{2}{c|}{ Patients with ESRD without diabetes } \\
\cline { 2 - 5 } & Male & Female & Male & Female \\
\hline Number & 2026 & 1871 & 2888 & 2209 \\
\hline Percentage & 52.0 & 48.0 & 56.7 & 43.3 \\
\hline Age (median) & $68.0 \pm 11.2^{*}$ & $73.0 \pm 11.5^{*}$ & $69.0 \pm 14.2^{*}$ & $72.0 \pm 13.9^{*}$ \\
\hline Age (average) & 67.5 & 70.8 & 67.1 & 69.1 \\
& $(95 \% \mathrm{Cl}: 67.0-67.9)$ & $(95 \% \mathrm{Cl}: 70.3-71.3)$ & $(95 \% \mathrm{Cl}: 66.6-67.6)$ & $(95 \% \mathrm{Cl}: 68.6-69.7)$ \\
\hline
\end{tabular}

${ }^{\star}$ Average \pm standard deviation.

Table III. Percentage rates in age groups for all-cause mortality in males and females in diabetic and non-diabetic patients with end-stage renal disease in Poland in 2012, based on the databases of the National Health Fund and the Central List of the Insured

\begin{tabular}{|lcccc|}
\hline \multirow{2}{*}{$\begin{array}{l}\text { Age range } \\
\text { [years] }\end{array}$} & \multicolumn{2}{c|}{ Patients with diabetes $(\%)$} & \multicolumn{2}{c|}{ Patients without diabetes (\%) } \\
\cline { 2 - 4 } & Male & Female & Male & Female \\
\hline$<44$ & 1.41 & 1.09 & 4.76 & 2.57 \\
\hline $45-64$ & 28.51 & 15.69 & 25.82 & 36.06 \\
\hline $65-74$ & 29.79 & 26.31 & 24.84 & 43.97 \\
\hline$>75$ & 40.29 & 56.91 & 44.58 & 43.06 \\
\hline
\end{tabular}

Table IV. All-cause mortality rates for diabetic and non-diabetic patients with end-stage renal disease in Poland in 2012 by gender and per 100,000 representatives of the general population, based on the databases of the National Health Fund and the Central List of the Insured, having subtracted patients with diabetes

\begin{tabular}{|cccc|}
\hline \multicolumn{2}{|c}{ Patients with diabetes } & \multicolumn{2}{c|}{ Patients without diabetes } \\
\hline Male & Female & Male & Female \\
\hline $147.59 \pm 29.07^{\star}$ & $105.13 \pm 26.77^{\star}$ & $9.58 \pm 6.29^{*}$ & $6.87 \pm 2.27^{\star}$ \\
\hline
\end{tabular}

${ }^{\star}$ Average \pm standard deviation.

men, whereas $43.3 \%$ of those who were non-diabetic and died of ESRD were women.

Female diabetic and non-diabetic patients were older at the time of death than male diabetic $(p<0.001)$ and non-diabetic $(p<0.001)$ patients. At the time of death male diabetic patients were younger than male non-diabetic patients $(p<0.001)$, but female diabetic patients were older at the time of death than the non-diabetic female patients $(p<0.001)$ (Table II).
In the age group up to 44 years, death occurred three times more frequently in male non-diabetic patients than in male diabetic patients. In the same age group death was two times more frequent in female non-diabetic patients than in female diabetic patients (Table III). Table IV presents all-cause mortality rates for people with ESRD with diabetes per 100,000 representatives of the general population in Poland in 2012 and for non-diabetic patients per 100,000 representatives of the general population 
in Poland in 2012, having subtracted the number of people with diabetes. The all-cause mortality rate for diabetic patients was significantly higher than all-cause mortality for both male and female non-diabetic patients, $p<0.0001$. It was found that mortality was significantly higher, $p<0.0001$, in male patients as compared with female patients, for both diabetic and non-diabetic patients (Table IV).

\section{Discussion}

89,009 people died in the United States of America (USA) in 2013 of ESRD, which gives an average mortality rate of $27.91 / 100,000$ representatives of the general population [22]. 20-25\% of patients with ESRD die in the USA on an annual basis, whereas $35 \%$ of patients survive for 5 years. However, only $3 \%$ of patients with ESRD and kidney transplantation die within 5 years [23].

Our study showed that the average all-cause mortality rate for male and female patients with ESRD in Poland in 2011 was 17.66/100,000 of the representatives of the general population, and in 2012 it was 15.89/100,000 representatives of the general population. In 2013 the mortality rate was $12.50 / 100,000$ of the representatives of the general population. Over 3 years a decrease by $30 \%$ in the all-cause mortality in people with ESRD was observed in Poland.

Hoffman et al. proved that the impact of diabetes on survival after ESRD is time-dependent, but they did not prove the differences between sexes. In our study males up to 74 years of age with ESRD and diabetes had a higher mortality rate than females. An interesting result is that women older than 75 years had a higher mortality rate than men (Table III) [24]. Navaneethan et al. reported an increased risk for all-cause mortality among patients with diabetes and chronic kidney disease, who had $\mathrm{HbA}_{1 \mathrm{c}}$ levels $<6 \%$, and among those who had $\mathrm{HbA}_{1 \mathrm{c}}$ levels $\geq 9 \%$, but they do not compare the mortality with non-diabetic patients [6].

Tonelli et al. presented a meta-analysis of 39 studies from around the world and showed that the occurrence of end-stage renal disease increases the risk of death from $38 \%$ to $1100 \%$ [4].

De Jager et al. reported that death was 13-15 times more frequent in patients treated with haemodialysis as compared to the control group [11].

Janeczko et al. presented data on mortality rates for 26 years of observation of patients with type 2 diabetes as compared to mortality rates for representatives of the general population, and they showed that the standard mortality rate for men with diabetes and kidney diseases was 20 times higher, and for the same group of women it was 18 times higher, than the standard mortality rate for the representatives of the gener- al population [25]. Małyszko et al. reported that cardiovascular death was more frequent in patients with chronic renal failure [26]. Rutkowski et al. revealed that $53.5 \%$ of patients on dialysis in Poland die of cardiovascular diseases [27]. Gurm et al. observed that out of 55,189 patients with acute coronary syndrome, including 579 patients with renal replacement therapy (haemodialysis), $13 \%$ of the dialysed patients and $4.8 \%$ of those who did not receive renal replacement therapy died [28].

In the USA, $50 \%$ of patients with end-stage renal disease die of cardiovascular diseases [29]. In the USA the mortality rate for patients with chronic renal failure, as opposed to end-stage renal disease, amounted to $117.9 / 1000$ patients in 2013, whereby the rates for men and women were $128.7 / 1000$ patients per year and 110/1000 patients per year, respectively [29].

Other researchers reported the death rate in patients with end-stage renal disease who were treated with haemodialysis at the level of $22 \%$ in the United States, $16 \%$ in Europe, and 7\% in Japan [30, 31]. Having observed 3702 patients aged over 77 years of age, Kurella-Tamura et al. reported a mortality rate for renal replacement therapy patients per year at $58 \%$. For this group of patients, mortality per year in the pre-renal replacement period was 13\% [32].

Foley et al. reported that the mortality rate in male diabetic patients with end-stage renal disease was 30 times higher as compared to the mortality rate in the general population. Nine per cent of patients with end-stage renal disease died of cardiovascular diseases [1].

In our study all-cause mortality rates for female and male diabetic patients with end-stage renal disease in Poland in 2012 were more than 15 times higher than the all-cause mortality rate in non-diabetic patients with ESDR. All-cause mortality rates for patients with ESRD in Poland in 2012 per 100,000 representatives of the general population are presented in Table I. Various complex haemodynamic and metabolic factors, such as renal failure, age, hypertension, diabetes, lipid disorders, and lack of physical exercise, contributed to the increased risk of cardiovascular death [33-36].

Our research had certain limitations that prevented the determination of the cause of chronic renal failure, type of diabetes, metabolic control of diabetes, and occurrence of hypertension. The study was a retrospective study on patients reported to the Polish National Health Fund.

The study is a unique comparative study on allcause mortality in patients with ESRD conducted on two cross-sectional groups: patients with diabetes and patients without diabetes. 
Our research is based on the reported diagnoses of end-stage renal disease in Poland in 2011-2013. It is original and unique because it shows how the occurrence of diabetes can affect the all-cause mortality in patients with end-stage renal disease. The results of the study show the necessity to intensify healthcare for diabetic patients to prevent the development of complications of diabetes and related problems.

In conclusion, mortality rates for people with ESRD in Poland in 2012 were higher for men than for women in the general population and both in the group of diabetic and non-diabetic patients. Mortality rates for diabetic men and women with ESRD in Poland in 2012 were 15 times higher than mortality rates for non-diabetic men and women with ESRD. Special attention should be paid to the prevention and treatment of diabetes as ways of increasing life expectancy of patients with ESRD.

\section{Conflict of interest}

The authors declare no conflict of interest.

\section{References}

1. Foley RN, Parfrey PS, Sarnak MJ, et al. Clinical epidemiology of cardiovascular disease in chronic renal disease. Am J Kidney Dis 1998; 32: 112-9.

2. Foley RN, Hakim RM. Why is the mortality of dialysis patients in the United States much higher than the rest of the world? J Am Soc Nephrol 2009; 20: 1432-5.

3. Chien CC, Wang JJ, Sun YM, et al. Long-term survival and predictors for mortality among dialysis patients in an endemic area for chronic liver disease: a national cohort study in Taiwan. BMC Nephrol 2012; 13: 43.

4. Tonelli M, Wiebe N, Culleton B, et al. Chronic kidney disease and mortality risk: a systemic review. J Am Soc Nephrol 2006; 17: 2034-47.

5. Chu YW, Wu WS, Hsu CF, et al. Bidirectional association between ESRD dialysis and diabetes: national cohort study. PLoS One 2017; 12: e0173785.

6. Navaneethan SD, Schold JD, Jolly SE, et al. Diabetes control and the risks of ESRD and mortality in patients with CKD. Am J Kidney Dis 2017; 70: 191-8.

7. Kayar Y, Agin M. The relationship between demographic and anthropometric characteristics and diabetic complications and number of hospitalizations in hospitalized diabetic patients. Arch Med Sci Civil Dis 2019; 4: e7-e15.

8. Yelumalai S, Giribabu N, Karim K, et al. In vivo administration of quercetin ameliorates sperm oxidative stress, inflammation, preserves sperm morphology and functions in streptozotocin-nicotinamide induced adult male diabetic rats. Arch Med Sci 2019; 15: 240-9.

9. Teng Y, Wang S, Wang N, et al. STOP-bang questionnaire screening for obstructive sleep apnea among Chinese patients with type 2 diabetes mellitus. Arch Med Sci 2018; 14: 971-8.

10. Sutkowski L, Matyja M, Pasternak A, et al. WHOQOL-BREF survey of quality of life among dialyzed end-stage renal disease patients. Arch Med Sci Civil Dis 2018; 3: e112-20.
11. de Jager DJ, Grootendorst DC, Jager KJ, et al. Cardiovascular and noncardiovascular mortality among: patients starting dialysis. JAMA 2009; 302: 1782-9.

12. Bloembergen WE, Port FK, Mauger EA, et al. Causes of death in dialysis patients: racial and gender differences. J Am Soc Nephrol 1994; 5: 1231-42.

13. Villar E, Remontet L, Labeeuw M, et al. Effects of age, gender, and diabetes on excess in end stage renal failure. J Am Soc Nephrol 2007; 18: 2125-34.

14. Lastra G, Manrique C, Sowers JR. Obesity, cardiometabolic syndrome, and chronic kidney disease: the weight of the evidence. Adv Chronic Kidney Dis 2006; 13: 365-73.

15. Act of 27.08.2004 on health care services financed from public funds. Journal of Laws 2008, No. 164, item 1027, as amended [In Polish].

16. Regulation of the Minister of Health of 11 January 2010 amending the regulation on guaranteed benefits in the field of health programs. Journal of Laws 2010, No. 05, item 29, as amended [In Polish].

17. Regulation of the Minister of Health of 2 March 2010 amending the regulation on guaranteed benefits in the field of hospital treatment. Journal of Laws of 2010, No. 30, item 157, as amended [In Polish].

18. Order No. 101/2007/DGL of the President of the National Health Fund dated 5 November 2007 amending the Order on the adoption of "Detailed information materials on proceedings concerning the conclusion of healthcare contracts and the implementation and financing of healthcare contracts type: hospital treatment [In Polish].

19. Order No. 36/2008/DGL of the President of the National Health Fund of 19 June 2008 on defining the conditions for concluding and implementing contracts such as hospital treatment in the field of therapeutic health programs [In Polish].

20. PESEL. Available at: http://www.msw.gov.pl/portal/pl/ 381/32/PESEL.html (Accessed: 10.10.2017) [In Polish].

21. Central Statistical Office. Size and structure of population and vital statistics in Poland in 2012. Available at: http://stat.gov.pl/obszary-tematyczne/ludnosc/ludnosc/ ludnosc-stan-i-struktura-ludnosci-oraz-ruch-naturalnyw-przekroju-terytorialnym-stan-w-dniu-31-xii-2012-r-, 6,11.html (Accessed: 10.10.2017) [In Polish].

22. Wierzba W, Pinkas J, Karnafel W, et al. Evaluation of the incidence of aortic aneurysms in patient with and without diabetes in Poland in 2012 based on the database of the National Health Fund. Arch Med Sci 2019; 15: 607-12.

23. U.S. Renal Data System. USRDS 2013. Annual Data Report: Atlas od End-Stage Renal Diseases in the United States, National Institute of Health, National Institute of Diabetes and Digestive and Kidney Diseases. Bethesda 2014.

24. Hoffmann F, Haastert B, Koch M, et al. The effect of diabetes on incidence and mortality in end-stage renal disease in Germany. Nephrol Dial Transplant 2011; 26: 1634-40.

25. Janeczko D, Tuszyńska A, Kopczyński J, et al. Umieralność w kohorcie chorych na cukrzycę typu 2 w czasie 26-letniej obserwacji w porównaniu do umieralności populacji lekarzy. Diabetol Pol 2003; 10: 172.

26. Małyszko J, Bachorzewska-Gajewska H, Tomaszuk-Kazberuk A, et al. Cardiovascular disease and kidney transplantation-evaluation of potential transplant recipient. Pol Arch Int Med 2014; 124: 608-16.

27. Rutkowski B, Lichodziejewska-Niemirko M, Gruda R, et al. Raport o strukturze leczenia nerkozastępczego w Polsce w 2005 roku. Gdańsk 2006. 
28. Gurm HS, Gore JM, Anderson FA, et al. Comparison of acute coronary syndrome in patients receiving venous not receiving chronic dialysis (from the Global Registry of Acute Coronary Events [GRACE] Registry). Am J Cardiol 2012; 109: 19-28.

29. U.S. Renal Data System. 2015 USRDS. Annual Data Report: Epidemiology of kidney disease in the United States, National Institutes of Health, National Institute of Diabetes and Digestive and Kidney Diseases. Bethesda 2015.

30. Goodkin DA, Young EW, Kurokawa K, et al. Mortality among hemodialysis patients in Europe, Japan, and the United States: case mix effects. Am J Kidney Dis 2004; 44: 16-21.

31. Iseki K. Chronic kidney disease in Japan. Intern Med 2008; 47: 681-9.

32. Kurella-Tamura M, Covinsky KE, Chertow GM. Functional status of elderly adults before and after initiation of dialysis. N Engl J Med 2009; 361: 1539-47.

33. Cetin $H$, Agin $M$, Kayar $Y$, et al. The relation between smoking and smoker timing and diabetic complications in type 2 diabetes mellitus patients. Arch Med Sci Civil Dis 2018; 3: e95-102.

34. Luke RG. Chronic renal failure - a vasculopathic state. N Engl J Med 1998; 339: 841-3.

35. Kasike BL. Risk factors for accelerated atherosclerosis in renal transplant recipients. Am J Med 1998; 84: 985-92.

36. Levey AS, Beto JA, Coronado BE, et al. Controlling the epidemic of cardiovascular disease in chronic renal disease: what do we know? What do we need to learn? What do we go from here? National Kidney Foundation Task Force on Cardiovascular Disease. Am J Kidney Dis 1998; 32: 853-906. 